\title{
A Personalized e-Learning Framework
}

Mohammed M. Alhawiti ${ }^{1}$ (iD)
Yasser Abdelhamid' ${ }^{2}$ (ID

\begin{abstract}
With the advent of web based learning and content management tools, e-learning has become a matured learning paradigm, and changed the trend of instructional design from instructor centric learning paradigm to learner centric approach, and evolved from "one instructional design for many learners" to "one design for one learner" or "many designs for one learner". Currently, there are mature technologies that can lead to the construction of a personalized e-learning environment, namely: Ontology, Semantic web, learning objects, and content management systems. In this paper, a personalized e-learning framework is proposed, where learning objects are classified according to their suitability for the different types and styles of learning, and where these learning objects are offered to individual learners according to their personal preferences, skills and needs.
\end{abstract}

\section{Keywords: Web-based learning, Technology adoption and diffusion of e-learning, E-learning personalization, Adaptive} learning, E-learning personalization framework.

\section{Contents}

1. Introduction

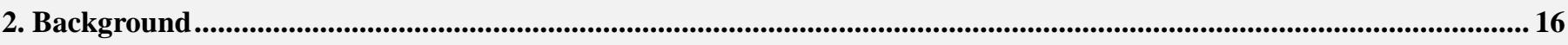

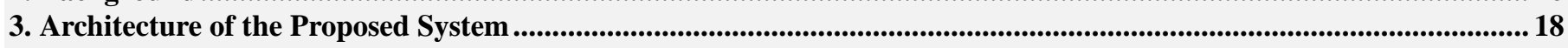

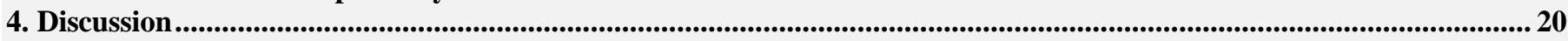

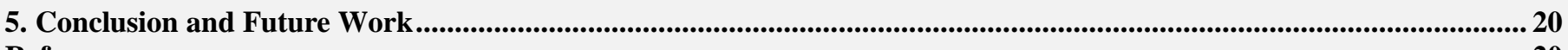

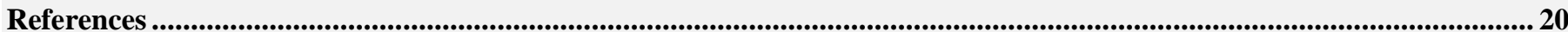

Citation | Mohammed M. Alhawiti; Yasser Abdelhamid (2017). A Personalized e-Learning Framework. Journal of Education and e-Learning Research, 4(1): 15-21.

DOI:

ISSN(E) :

10.20448/journal.509.2017.41.15.21 Crossref

$\operatorname{ISSN}(\mathbf{P})$ :

Licensed:

2410-999

Contribution/

2518-0169

Funding:

This work is licensed under a Creative Commons Attribution 3.0 License $(\mathrm{cc}) \mathbf{E Y}$

This project was funded by the Deanship of Scientific Research at the University of Tabuk.

Transparency:

This project was funded by the Deanship of Scientific Researc
The authors declare that they have no conflict of interests.

History:

Ethical:

Publisher:

The authors confirm that the manuscript is an honest, accurate, and transparent account of the study was reported; that no vital features of the study have been omitted; and that any discrepancies from the study as planned have been explained. Received: 1 February 2017/ Revised: 8 March 2017/ Accepted: 14 March 2017/ Published: 20 March 2017

This study follows all ethical practices during writing.

Asian Online Journal Publishing Group 


\section{Introduction}

In e-learning environments, instructional design has evolved from one instructional design for many learners to one design for each learner or many designs for each learner (Chorfi and Jemni, 2003). It is a fact that learners have varying characteristics and skills that affect the way they learn best.

In order to fulfill this target, many learning sequences should be developed for the same course using different course components. For these components to be reusable, they have to be designed in a way that makes it selfcontained, and small enough to facilitate its reuse in different contexts. According to this view, a huge number of components will be generated, and the problem will be to locate the required components and to put them in their place in the intended sequence of learning. To facilitate searching for learning components, each component needs to be marked with information that identify its different aspects including its subject matter information and other properties that characterize each of these components. A standard model of the produced learning components must be used to support its sharing and reuse among the community of learning courses authors. Also, the terminology and vocabulary used to describe the learning components must be unified.

To enable machines to help the authors in building learning sequences, data about components and their properties should be modeled and encoded in a machine exchangeable form. There must be an intelligent process that can match the characteristics of available learning components against those of the individual learners. This process will use its knowledge about the characteristics of learners and help them in adapting the learning sequence that suits their preferences. Although it is a complicated process, the authors believe that the current information technologies are able to fulfill the aforementioned requirements. Utilization of these technologies come in four stages: Authoring, Characterization, Delivery, and Feedback.

At the authoring stage, the course designer needs a system that helps in building the structure of the intended course, that is breaking down the course into a number of modules, each module is divided into a number of lessons, and finally each lesson is represented by a number of learning objects which are the primitive components to be delivered to the learner. Learning content management system is the suitable tool for this stage, as it provides all the authoring and design facilities for the course designer to build and organize his/her course. Characterization stage involves description, tagging, and classification of learning objects, this stage will allow learning objects to be shared or reused in different courses. Ontology provides the possibility to describe learning objects by formally specifying its characteristics. This will allow for founding the language that will be used later in the delivery stage for matching the properties of learning objects against the personal characteristics, skills and preferences of the learner, and suggesting the most suitable learning objects for them. Finally, the feedback stage is needed to build the knowledge upon which specific learning objects are recommended for each individual learner, either according to the learner's own previous selections and preferences, or according to those of other similar learners who have similar preferences.

This research project introduces the layout of a proposed framework that combines learning objects, ontology, semantic web, and content management systems to enable the delivery of a personalized course plan for each individual learner. In section 2 , the authors provide a sufficient background about ontology, learning objects, semantic web, and content management systems. In section 3, the layout of the proposed framework is introduced. Finally, section 4 is for discussion and conclusions.

\section{Background}

Current technology has the potential to construct an e-learning environment that is capable of acquiring preferences of learners, building and managing sharable and reusable semantically modeled learning entities, and providing customized e-learning services for each individual learner according to his/her preferences and personal characteristics. These technologies are: learning objects, ontology, semantic web, and content management systems. In addition to introducing the concept of e-learning personalization, the reader will be provided with an adequate coverage about each of these technologies and the role of each of them in the proposed framework.

\section{A. Personalized e-Learning}

Personalization in e-learning is an education related technology that provides the possibility of creating different learning sequences for the different learners, based on their personal needs and preferences (Devedžiü, 2006). Researchers have adopted different strategies for achieving personalization in e-learning domain. For example, PERSO recommends courses to be provided to learners according to their level and their media preferences using Case Based Reasoning (CBR) (Chorfi and Jemni, 2003). Tools for building personalized hyper books, like Metalinks, has been used to build a geology personalized hyper book according to the learner's level of knowledge, media preferences and learning goals (Murray, 2003). Course planning tools like PASER, have been used for building personalized course plans based on learners' goals and their level of knowledge using domain ontology (Kontopoulos et al., 2008). Web mining was another technique that have been used to deliver learning content to learners according to their preferences and needs (Khribi et al., 2007).

It is worth mentioning that not only learner's preferences determine the appropriate personalization strategy, but also learning courses characteristics and teachers' preferences are among the factors that affect the selection of such strategies (Essalmi et al., 2010; Essalmi et al., 2010).

\section{B. Learning Objects}

Recently, sharing and reuse of learning content has gained a lot of interest that led to the emergence of the concept of learning objects. Inspired by the idea of object-oriented programming, the idea of learning objects is to build learning courses using libraries of small blocks, these blocks are self-contained reusable components that are associated with metadata to facilitate its sharing and reuse (Duval, 2002).

Traditional learning content came into large blocks that made it hard to include it in any learning sequence other 
than the original intended one. Small size and self-containment are among the most characterizing features of learning objects. As learning component gets smaller, its chance for being reused in different contexts and different learning sequences becomes larger, and the more it becomes self-contained and independent of other components, the more it becomes easy to reuse in different contexts. Learning objects can also be grouped in larger collections to construct other larger bodies of learning structures.

In addition to the subject matter learning content included in the learning object, there are other information and metadata that are used to facilitate locating and searching for them. Learning object metadata may include information like type of learning object, format, and teaching or interaction style. Learning objects can be classified into presentation objects, which introduce specific subject matter through direct instruction and presentation resources, practice objects, which allow learning of certain procedures through practical activities like drill, interactive applications, educational games or representations that allow practice and learning of certain procedures, simulation objects, which allow learning through virtual representation of processes and real-life systems, conceptual models, which allow learning of key concepts related to a specific subject matter, information objects, which allow learning by displaying information organized and represented with modalities, and contextual representation, that is data displayed as it emerges from represented authentic scenario (Churchill, 2007).

\section{Ontology}

Ontology is the explicit formal specification of terms and the relationship between them in a specific domain (Gruber, 1993). It defines a common vocabulary for researchers to share information in a specific domain, and includes machine-interpretable definitions of basic concepts and their relationships in that domain. Ontology is becoming of increasing importance to a large number of applications, such as knowledge-based systems, information exchange, the semantic web, and application integration. Many disciplines have developed their own standard ontologies that domain experts can use to share and annotate information in their fields.

Ontology is considered to be a highly suitable means of supporting educational-technology systems (Mizoguchi and Bourdeau, 2000; Aroyo et al., 2002). The increasing importance of the semantic web, which is based on ontology, is strengthening this argument (Berners-Lee et al., 2001). It has a promising role in the field of instructional design and the development of course content, as it can represent knowledge about content, supports course authors in creating content and provides easy accessibility of course content by students. Hence, it is strongly expected that ontology might be useful in the domain of education (Boyce and Pahl, 2007).

Ontologies for the Use of digital learning Resources and semantic Annotations on Line (OURAL) is a research project that defines ontology in the e-learning domain including problem-situation, problem solving, critical analysis, case study, debate, cyber quest, project, exercise, etc (Grandbastien et al., 2007).

Ontologies for e-learning systems in higher education (Bucos et al., 2010) is a semantic web that was implemented using Protégé-OWL and defines user profile ontology, the person ontology, the contact ontology and educational activities ontology among other classes in the domain of higher education.

Information and Communication Technologies (ICT) in education ontology (Chin and Chang, 2011) provides a central repository of classified knowledge of ICT in the education domain. ICT ontology consists of concepts like ICT curriculum, ICT job, ICT skill and ICT research.

European credit vocational system (Yang and Chen, 2010) uses ontologies in the construction of the educational resources library, to provide a common access to the information regarding the qualification systems of nine European countries.

A number of recent studies in the domain of e-learning development focused on the use of ontology in supporting adaptive learning and personalization of course content (Sedleniece and Cakula, 2012). The idea is based on the fact that every learner prefers certain types of training material according to his/her personal learning style, needs and interests, and ontology can fill the gap to structuring course content in a way that facilitates easy delivery of course content to different styles of individual learners. Ontology can help learners to use learning contents that match their personal preferences by using information that has formal specific meaning about these learning contents. Ontology also can be used for imposing a structure on the learning contents of a specific subject which helps both the instruction designer and the learner in the learning process.

\section{Semantic Web}

The World Wide Web (WWW) has a huge amount of documents and lots of information, only accessible by human users. Knowledge in the Internet is notorious for its vastness, semantically duplicated terms, vagueness, incompleteness, uncertainty, and inconsistency. Search engines currently use keyword searches within these documents to find text that a user is looking for. Computers cannot understand the contents of the documents; they can only present their contents. To enable machines to understand information published in the web documents, there must be a way for giving this information well-defined meanings. This will enable also better communication between human and machines.

The semantic web provides a mechanism for formatting data into machine readable form, describing individual data using properties defined in globally accessible schemas, matching local references to entities against various kinds of standard names, and enabling a range of inferences over data in scalable ways.

The semantic web uses a data model named RDF (Resource description Framework) that is based on the idea of making statements about resources in web sites. The statements are constructed in the form of (Subject, Predicate, Object) triples, where Subject represents a resource, Predicate represents a property of the resource, and Object is a value of the property in form of a resource or a literal. Semantic Web technologies such as RDFa (Adida and Birbeck, 2008) allow webpage designers to embed RDF in their webpages for encoding information to be processed by machines. The RDF set of triples builds a directed graph, called RDF graph, where the subject and object are nodes and the predicate is a labeled directed edge from the subject to the object. 


\section{E. Content Management Systems}

A content management system is a kind of software that allows creation of learning content as well as providing all the functions required to modify, organize, delete, or publish that content. It is also capable of managing workflow in a shared and collaborative environment (Rockley et al., 2003; White, 2005; Tseng et al., 2008). Learning management systems are varying from just management of educational information to delivery of online learning content, and other features including collaboration, sharing, result analysis, and many other features. Two types of learning systems must be distinguished: Learning Management Systems (LMS), and Learning Content Management Systems (LCMS). Learning management systems control management and delivery of online courses, in addition to other tasks related to the management of student records, and tracking their performance. Learning content management systems are software environments that provide the facilities of developing, storing, managing, reusing and delivery of learning content repositories. Using LCMS, course development is never done entirely from scratch. It provides the facility of rapidly assembling courses out of reusable objects stored in the shared learning content repository.

Products of LMS may include student administration and registration, activity event management, reporting, certification management, and performance tracking, while LCMS products may include functionalities like collaborative content management, workflow integration, publishing and template driven content development.

\section{F. Adaptive Learning Management Systems}

Adaptive learning has gained increased attention in the last few years, many research efforts have been forwarded to experimenting the idea and proving its efficiency. In 2008 a research group developed an adaptive learning system based on personalization information, learning behavior and personal learning style (Tseng et al., 2008). They conducted an experiment to evaluate the performance of the proposed model. The results revealed that the proposed approach can be helpful in improving both the learning achievement and learning efficiency of individual students. In 2014, a research group applied activity theory to design an adaptive e-learning systems, where the activity theory is a framework to study human's behavior at learning. They concluded that activity theory is a useful framework to design adaptive e-learning systems and provide student-centered education (Peña-Ayala $e t$ al., 2014).

(SDAL) is a novel Statistical sub-Domain Adaptation Learning framework. The proposed framework concentrated on problems such as improving the efficiency of the algorithms to set the parameters that affect learning methods (Gao et al., 2015).

\section{G. Learning Styles}

Learning styles are ways of learning. A preferred learning style is the way in which a student learns best, which reflects the relative strengths or weaknesses of that student's underling cognitive learning skills. There are many research efforts that assert the fact that students and trainees learn effectively with teaching methods that fulfill their learning preferences ( $\mathrm{Li}$ et al., 2008). Learning style can be defined as the cognitive characteristics, affective and psychological behaviors that indicate the way learners perceive, interpret and react to learning environments (Honey and Mumford, 1992). They are also defined as the composite of cognitive characteristics, affective and psychological factors that influence the way individuals interact and respond to learning environments (Duff and Duffy, 2002).

Research on learning styles has been approached from different perspectives including web-based education perspective on learning style (Garcia et al., 2007) aesthetic experience (Welsh et al., 2007) using business case studies in learning process (Duff et al., 2008) problem-solving strategies within learning styles (Metallidou and Platsidou, 2008) preferred learning styles (Peters et al., 2008) and adaptive learning system perspective of learning styles (Tseng et al., 2008).

Multiple Intelligence (MI) theory indicates that there are at least seven learning styles including Interpersonal, intra-personal, body/kinesthetic, visual/spatial, logical/mathematical, verbal/linguistic, and musical/rhythmic. Recent educational literature, focus on a simplified list of learning styles: Auditory, Visual, and Tactile (Lazear, 1991).

A student with an auditory learning style learns best when information is delivered in auditory formats such as lectures, discussions, oral readings, audio recordings, or podcasts. Auditory learners do well in classroom settings where professor lectures and student discussions are the norm. These students also do well with taped courses and group study situations. A student with a visual learning style learns best when information is presented in visual formats such as books, articles, web pages, images, videos, or diagrams. Visual learners do well with class handouts, power point presentations, movies, and chalkboards. These students take detailed notes, highlight their texts, and use flow charts for study aids. A student with a tactile learning style learns best when information is conveyed in "handson" settings such as trade positions, labs, workshops, or participatory classes. Tactile learners respond well to touching and creating things in areas such as art and science. These students want to hold and manipulate the subject matter, rather than merely viewing its image (Gilakjani, 2012).

\section{Architecture of the Proposed System}

The proposed framework integrates the capabilities of content management systems, ontology, semantic web, and learning objects to build an adaptive e-learning environment. The main target of the proposed framework is to produce standardized repositories of sharable and reusable learning objects that can be used to personalize the process of e-learning for the individual learners by acquiring their personal characteristics, and preferences, and adapting their learning plan according their specific characteristics. This section introduces a description of the overall architecture of the proposed framework, and the role of each of its components.

As shown in Figure I the proposed framework consists of four main modules: learning content authoring module, tagging module, intelligent personalization module, and learning content delivery module. 


\section{A. Learning Content Authoring Module}

The learning content authoring module is a sub-system of the learning content management system that provides the facilities of creating, modifying, and managing learning objects. The learning object can be described in two ways: The asset or the content of the learning object in the form of video tutorials, presentations, text notes, training instructions etc..., and the learning object metadata which adds information about the learning objects in the form of tags and helps in easily locating them. Learning objects with effective meta-tags facilitate content maintenance, search, and management. They also allow for immediate customization of course content based on criteria that the learner selects.

The institute of Electrical and Electronics Engineers standards association (IEEE) has published a standard for Learning Object Metadata (IEEE 1484.12.1 - 2002), for the description of learning objects. According to this model, attributes of learning objects have been classified into nine main categories including general attributes like title, language and description, and technical information like format, size and location, and educational attributes like interactivity level, learning resource type, and context, and many other attributes that describe the different aspects of the learning object.

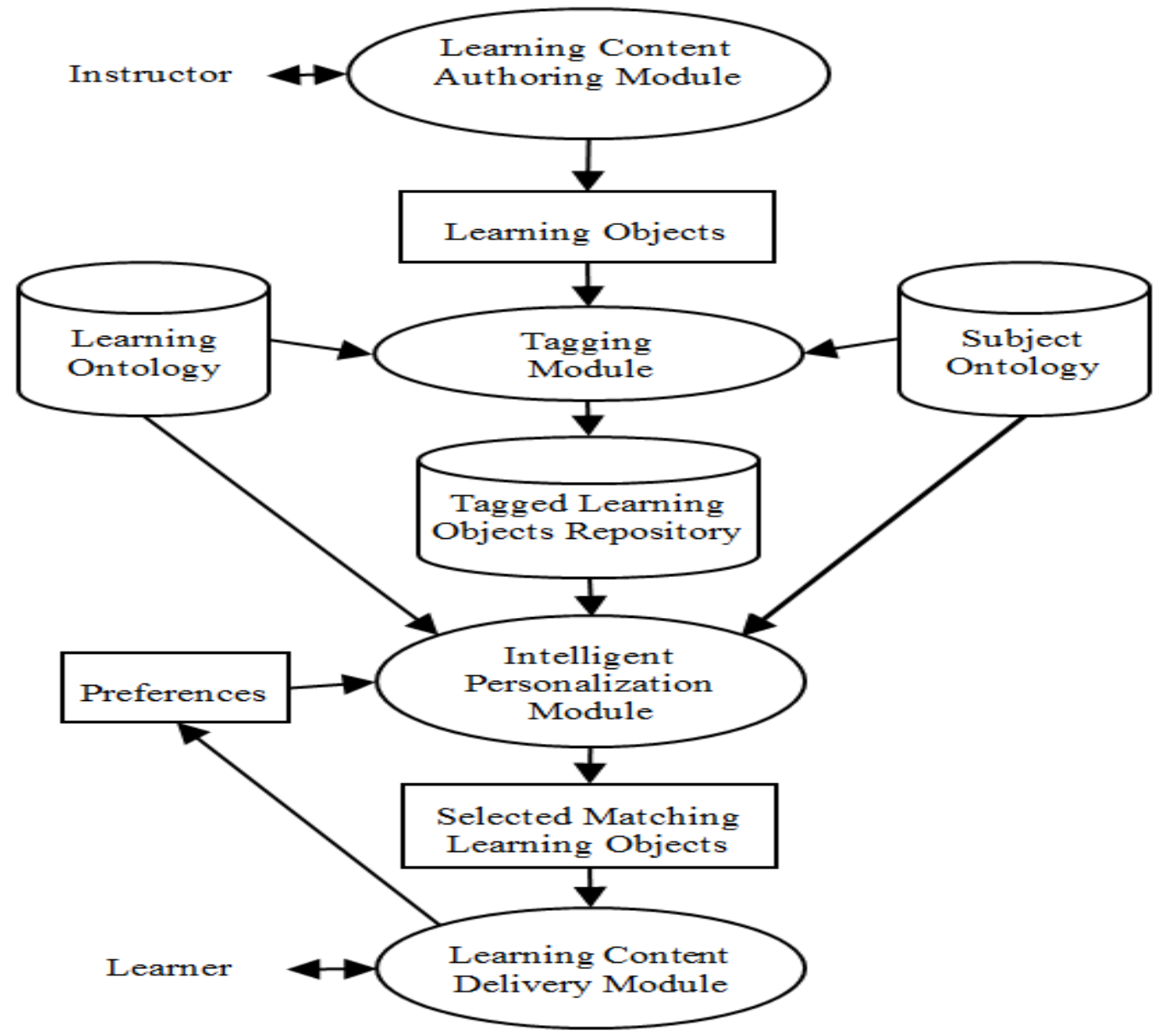

Figure-I. Proposed e-learning personalization framework

\section{B. Tagging Module}

Tagging is the process of adding special annotations or marks that attach a piece of information to a resource or an object for future referral. There are many purposes for tagging objects, users usually tag objects for the purpose of future retrieval of the objects by themselves or by others. They also use tags for sharing their ideas about objects with other users, or to attract attention to specific resources, or to put self-referential tags to mark their contributions, or to put an evaluation for a specific object (Gupta et al., 2010).

This sub-system uses ontology for attaching meta-data to each learning object. Generally, there are two types of ontology that can be used by the tagging module: Course subject ontology, and Learning ontology. Course subject ontology includes knowledge related to the concepts of a specific learning course subject and the relations between them, while learning ontology includes knowledge related to the concepts of learning as a general domain and the relations between them. Tagged learning objects are stored in a repository to be used by the learners through the delivery module.

\section{Intelligent Personalization Module}

In the previous stage, learning objects are attached with subject ontology tags and learning ontology tags. The intelligent personalization module uses these tags for determining which of these learning objects is suitable for each learner. By determining the learning style of the learner as well as his/her previous feedback about consumed learning objects, the intelligent personalization module will be able to set the characteristics of learning objects that match the preferences of the learner.

\section{Learning Content Delivery Module}

The content delivery module is the front end system that deals directly with the learner. In addition to offering learning sequences to the learner, the proposed content delivery module keeps a record of the learning objects consumed by each learner, and the feedback that can be used in dynamically adapting his/her learning sequence. 


\section{Discussion}

The old days of having one instructional design for all learners has gone. Learners with different learning styles need different learning sequences to elevate their performance in the learning process. Current e-learning and information technologies has the potential to support multiple instructional designs for different learners if it is integrated properly. Learning objects, and learning management systems have been around many years ago but the personalization requirement couldn't be fulfilled since a huge amount of work is needed to be done by the authors of the e-learning courses.

This research project addresses this requirement and introduces ontology and the semantic web technologies for doing the hard work of classifying the produced learning objects, acquiring preferences of individual learners and using this information in determining the most suitable learning objects for each individual learner. The proposed framework is organized into four stages: Authoring, Characterization, Delivery, and Feedback. At the authoring stage, a learning content authoring module is used for building learning objects using a standard learning object model to support sharing / reuse. At the characterization stage, the tagging module is used for adding meta-data extracted from subject matter ontology and learning domain ontology to characterize each learning module according to its content, and relevance to specific styles of learning. At the delivery stage, an intelligent personalization module is used to search learning object repositories for the most suitable elements according to the preferences of the learner, and forward them to the learning content delivery module that is responsible for both recommending these learning objects to the learner and acquiring his/her learning style, and preferences to be taken in consideration in consequent adaptation of his/her learning sequence.

\section{Conclusion and Future Work}

This research has drawn a road map for building a fully personalized e-learning system. The used technologies were around long ago, but haven't been integrated in a way that fulfills the personalization target. Future research in this area will include the following:

- Implementation of a learning objects authoring tool based on the structure of the (IEEE 1484.12.1 - 2002) standard, to support sharing and reuse of learning objects.

- Implementation of course / subject ontology building tool that helps in constructing the concepts related to a specific subject and the relations between them.

- Implementation of a learning ontology building tool that helps in constructing the concepts of learning and the relations between them.

- Implementation of learning objects characterization system that uses the related ontology in characterizing learning objects and keeping them in searchable repositories.

- Implementation of an intelligent personalization system that acts as an agent that takes care of the preferences of the learner and searches the learning object repositories on the web for suitable ones for the learner.

- Implementation of a learning objects delivery system that interacts with the learner, suggests learning sequences and acquires feedback from the learner for consequent adaptation of his/her learning sequence.

\section{References}

Adida, B. and M. Birbeck, 2008. RDFa primer - bridging the human and data webs. W3C Working Group Note. Retrieved from http://www.w3.org/TR/xhtml-rdfa-primer/.

Aroyo, L., D. Dicheva and A. Cristea, 2002. Ontological support for web courseware authoring. In Cerri, S.A., Gouarderes, G. \& Paraguacu, F. (Eds.), Proceedings of Intelligent Tutoring Systems, Berlin: Springer. pp: 270-280.

Berners-Lee, T., J. Hendler and O. Lassila, 2001. The semantic web. Scientific American, 284(5): 34-43. View at Google Scholar

Boyce, S. and C. Pahl, 2007. Developing domain ontologies for course content. Educational Technology \& Society, 10(3): 275-288. View at Google Schola

Bucos, M., B. Dragulescu and M. Veltan, 2010. Designing a semantic web ontology for elearning in higher education. In Proceedings of IEEE 9th International Symposium on Electronics and Telecommunications. pp: $415-418$.

Chin, K.L. and E. Chang, 2011. A sustainable ICT education ontology. In Proceedings of 5th IEEE International Conference on Digital Ecosystems and Technologies, Korea. pp: 350-354.

Chorfi, H. and M. Jemni, 2003. PERSO: A system to customize e-training. 5th International Conference on New Educational Environments, Lucerne, Switzerland.

Churchill, D., 2007. Towards a useful classification of learning objects. Educational Technology Research and Development, 55(5): 479-497. View at Google Scholar | View at Publisher

Devedžiü, V., 2006. Semantic web and education. Berlin: Springer-Verlag.

Duff, A., A. Dobie and X. Guo, 2008. The influence of business case studies and learning styles in an accounting course: A comment. Accounting Education, 17(2): 129-144. View at Google Scholar $\mid$ View at Publisher

Duff, A. and T. Duffy, 2002. Psychometric properties of Honey 6 Mumford's learning style questionnaire (LSQ). Personality and Individual Differences, 33(1): 147-163. View at Google Scholar | View at Publisher

Duval, E., 2002. 1484.12.1 IEEE standard for learning object metadata, IEEE Learning Technology Standards Committee. Retrieved from http://ltsc.ieee.org/wg12/.

Essalmi, F., B. Jemni, Ayed. L. and M. Jemni, 2010. An ontology based approach for selection of appropriate E-learning personalization strategy, DULP Workshop. Proceedings of The 10th IEEE International Conference on Advanced Learning Technologies, Sousse, Tunisia, 10: 724-725.

Essalmi, F., B.A.L. Jemni, M. Jemni, Kinshuk and S. Graf, 2010. A fully personalization strategy of E-learning scenarios. Computers in Human Behavior, 26(4): 581-591. View at Google Scholar $\mid$ View at Publisher

Gao, J., R. Huang and H. Li, 2015. Sub-domain adaptation learning methodology. Information Sciences, 298(C): 237-256. View at Google Scholar View at Publisher

Garcia, P., A. Amandi, S. Schiaffino and M. Campo, 2007. Evaluating bayesian networks'precision for detecting students' learning styles. Computers \& Education, 49(3): 794-808. View at Google Scholar View at Publisher

Gilakjani, A., 2012. Visual, auditory, kinaesthetic learning styles and their impacts on english language teaching. Journal of Studies in Education, 2(1): 104-113. View at Google Scholar $\mid$ View at Publisher

Grandbastien, M., F. Azouaou, C. Desmoulins, R. Faerber, D. Leclet and C. Quénu-Joiron, 2007. Sharing an ontology in education: Lessons learnt from the OURAL project. Proceedings of 7th IEEE International Conference on Advanced Learning Technologies. 
Gruber, T.R., 1993. A translation approach to portable ontology specification. Knowledge Acquisition, 5(2): 199-220. View at Google Scholar $\mid$ View at Publisher

Gupta, M., R. Li, Z. Yin and J. Han, 2010. Survey on social tagging techniques. ACM SIGKDD Explorations Newsletter, 12(1): 58-72. View at Google Scholar $\mid$ View at Publisher

Honey, P. and A. Mumford, 1992. The manual of learning styles. Maidenhead: Peter Honey Publications.

Khribi, M.K., M. Jemni and O. Nasraoui, 2007. Toward a hybrid recommender system for e- learning personalization based on web usage mining techniques and information retrieval. Proceedings of World Conference on E-Learning in Corporate, Government, Healthcare, and Higher Education (E-learn 2007), 7(1): 6136-6145.

Kontopoulos, E., D. Vrakas, F. Kokkoras, N. Bassiliades and I. Vlahavas, 2008. An ontology based planning system for e-course generation. Expert Systems with Applications, 35(1-2): 398-406. View at Google Scholar $\mid$ View at Publisher

Lazear, D., 1991. Seven ways of teaching: The artistry of teaching with multiple intelligences. Menlo Park, CA: Addison Wesley.

Li, Y.S., P.S. Chen and S.J. Tsai, 2008. A comparison of the learning styles among different nursing programs in Taiwan: Implications for nursing education. Nurse Education Today, 28(1): 70-76. View at Google Scholar $\mid$ View at Publisher

Metallidou, P. and M. Platsidou, 2008. Kolb's learning style inventory-1985: Validity issues and relations with metacognitive knowledge about problem-solving strategies. Learning and Individual Differences, 18(1): 114-119. View at Google Scholar | View at Publisher

Mizoguchi, R. and J. Bourdeau, 2000. Using ontological engineering to overcome common AI-ED problems. International Journal of Artificial Intelligence in Education, 11(2): 107-121. View at Google Scholar

Murray, T., 2003. Metalinks: Authoring and affordances for conceptual and narrative flow in adaptive hyperbooks. International Journal of Artificial Intelligence in Education, 13(2-4): 199-233. View at Google Scholar

Peña-Ayala, A., H. Sossa and I. Méndez, 2014. Activity theory as a framework for building adaptive e-learning systems: A case to provide empirical evidence. Computers in Human Behavior, 30: 131-145. View at Google Scholar $\mid$ View at Publisher

Peters, D., G. Jones and J. Peters, 2008. Preferred 'learning styles' in students studying sports-related programmers in higher education in the United Kingdom. Studies in Higher Education, 3(2): 155- 166. View at Google Scholar $\mid$ View at Publisher

Rockley, A., P. Kostur and S. Manning, 2003. Managing enterprise content: A unified content strategy. New Riders.

Sedleniece, M. and S. Cakula, 2012. Framework for personalized e-learning model. Proceedings WSEAS, Recent Researches in Communications and Computers. pp: 457-462.

Tseng, J.C.R., H.C. Chu, G.J. Hwang and C.C. Tsai, 2008. Development of an adaptive learning system with two sources of personalization information. Computers \& Education, 51(2): 776-786. View at Google Scholar $\mid$ View at Publisher

Welsh, M.A., G.E. Dehler and D.L. Murray, 2007. Learning about and through aesthetic experience: Understanding the power of experiencebased education. In Reynolds M \& Vince R. (Eds.), The handbook of experiential learning \& management education. Oxford: Oxford University Press.

White, M., 2005. The content management handbook. Facet Publishing.

Yang, F. and Y. Chen, 2010. Ontology based application framework for network education resources library. In Proceedings of 2 nd International Workshop on Education Technology and Computer Science. pp: $423-426$. 